\title{
Clinical characteristics and outcomes in elderly with coronavirus disease 2019 in Beijing, China: a retrospective cohort study
}

\author{
Wei Zhang ${ }^{1} \cdot$ Wei Hou ${ }^{1} \cdot$ Ronghua $\mathrm{Jin}^{1} \cdot$ Lianchun Liang $^{1} \cdot$ Bin Xu $\mathrm{Xu}^{1} \cdot$ Zhongjie Hu$^{1} \odot$
}

Received: 10 April 2020 / Accepted: 25 September 2020 / Published online: 10 October 2020

(c) Società Italiana di Medicina Interna (SIMI) 2020

\begin{abstract}
A novel human coronavirus, known as severe acute respiratory syndrome coronavirus 2 (SARS-CoV-2), has caused a global pandemic of coronavirus disease 2019 (COVID-19). In this study, we aimed to explore the clinical characteristics and outcomes in older patients with COVID-19. Ninety-one patients with SARS-CoV-2 infection were included in the study, 27 of which (29.67\%) were elderly. The median age of these 27 patients was 74.9 years (interquartile range 68-82; range 65-94 years), and 15 (55.56\%) were female. Elderly with COVID-19 in Beijing (China) were more likely to have underlying comorbidities and more frequently tended to have critical illness and suffer from more complications. The main treatments of the elderly consisted of symptomatic and respiratory support. The most frequent complications in the elderly were pleural effusion [10, (37.04\%)], secondary infection [7, (25.93\%)], and kidney damage [7, (25.93\%)]. Six (22.22\%) of the 27 elderly patients received invasive ventilation (three of them switched to extracorporeal membrane oxygenation). As of March 7, $20(74.07 \%)$ of the 27 elderly patients were discharged, two $(7.41 \%)$ were still hospitalized, and five died; the mortality in the elderly was $18.52 \%$. Age was associated with the mortality in patients with COVID-19 (OR 0.82; 95\% CI 0.70-0.97; $P=0.019$ ). Therefore, more attention should be paid to the treatment of comorbidities and complications in elderly patients.
\end{abstract}

Keywords 2019 novel coronavirus disease (COVID-19) · Elderly $\cdot$ Clinical characteristics · Outcome

\section{Introduction}

Coronavirus disease 2019 (COVID-19) is a severe acute respiratory syndrome (SARS)-like atypical pneumonia, which is a communicable disease that poses a serious public health threat $[1,2]$. The pathogen was identified as severe acute

Zhongjie $\mathrm{Hu}$

dr_huzhongjie@163.com

Wei Zhang

282495106@qq.com

Wei Hou

baoerlanglang@163.com

Ronghua Jin

93353503@qq.com

Lianchun Liang

1lc671215@sohu.com

$\mathrm{Bin} \mathrm{Xu}$

xubin1016@126.com

1

\footnotetext{
Department of Critical Care Medicine of Liver Disease, Beijing YouAn Hospital, Capital Medical University, No. 8 YouAn Men Wai Street, Beijing 100069, Fengtai, China
}

respiratory syndrome coronavirus 2 (SARS-CoV-2) [3]. Although studies on the biological characteristics of SARS$\mathrm{CoV}-2$ and clinical management of the disease have been conducted, our understanding of COVID-19 is still insufficient, especially concerning special populations, such as the elderly, pregnant women, and children. Preliminary data suggest that higher age is a risk factor for COVID-19 progression $[4,5]$. However, the impact of aging on COVID-19 still remains largely unknown.

Here, we retrospectively analyzed the clinical details of consecutive elderly patients with COVID-19 admitted to the Beijing YouAn Hospital. Our aim was to compare the characteristics, treatment options and outcomes between younger ( $<65$ years) and elderly ( $\geq 65$ years) patients with COVID-19. 


\section{Methods}

\section{Ethical approval}

The present retrospective study was performed in Beijing YouAn Hospital, Capital Medical University (Beijing, China). It was conducted in compliance with the principles of the Declaration of Helsinki. The ethics committee of our hospital waived written informed consent because of its retrospective nature and evaluation of only clinical data of the patients, involving no potential risk. Verbal informed consent from all patients or from the patient's legal representative if the patient was too unwell to provide consent.

\section{Patients}

Ninety-one adult patients suffering from COVID-19 were admitted to the Beijing YouAn Hospital for treatment from January 17, 2020 to February 29, 2020. The diagnostic criteria were according to the WHO interim guidance [2]. The following exclusion criteria were applied: patients under 18 years, pregnancy status, and incomplete data. The patients were divided into two groups: a young/middle-aged group ( $<65$ years) and an elderly group ( $\geq 65$ years).

\section{Data collection}

The information of the medical records collected from the hospital's electronic medical records included demographic data, epidemical history, past medical history, clinical features, laboratory data, and imaging findings on admission, as well as treatment, complications, and disease outcomes. The original data was created by a medical expert. The data was in excel file format. The electronic file was stored in a password protected computer which was in a independent locked office. Only the researchers had access. All the clinical data were checked by two trained researchers, respectively.

\section{Definitions}

The severity of COVID-19 was divided into four types based on the guidelines of the Diagnosis and treatment protocol for novel coronavirus infection induced pneumonia, published by the National Health Commission of China (trial version 7) [6]. The mild type was characterized by mild clinical symptoms and no pneumonia on imaging. The common type had clinical symptoms and imaging evidence of pneumonia, whereas the severe type was represented by any of the following conditions: respiratory distress, respiratory rate $(\mathrm{RR}) \geq 30$ breaths/min, blood oxygen saturation at rest $\leq 93 \%$, and partial arterial oxygen pressure $\left(\mathrm{PaO}_{2}\right)$ to fraction of inspired oxygen ratio $\left(\mathrm{FiO}_{2}\right) \leq 300 \mathrm{mmHg}$ $(1 \mathrm{mmHg}=0.133 \mathrm{kPa})$. The critically ill patients had severe conditions, such as respiratory failure requiring mechanical ventilation, shock, that were combined with the failure of other organs, which required intensive care unit (ICU) monitoring and treatment.

\section{Statistical analysis}

All data were analyzed by SPSS version 20.0 (Armonk, NY, USA). Continuous variables were expressed as mean \pm standard deviation (SD) and analyzed using Student's $t$ test or Mann-Whitney $U$ test. Categorical variables were expressed as number\% (\%) and analyzed using the $\chi^{2}$ test or Fisher's exact test. Univariate and multivariate analysis of prognostic factors were performed using the logistics regression. A two-sided $P$ value $<0.05$ indicated statistically significant differences.

\section{Results}

\section{Demographic data, epidemical history, comorbidities, and clinical classification}

The demographic data, epidemical history, comorbidities, and clinical classification of COVID-19 patients are presented in Table 1. Of the 91 patients with COVID-19, twenty-seven (29.67\%) patients were older than 65 years, with a median age of the elderly of 74.9 years [interquartile range (IQR) 68-82; range 65-94 years].

Of the 27 elderly patients, $10(37.04 \%)$ were local residents of Wuhan. One (3.70\%) of the patients lived outside Wuhan and was in contact with local residents of Wuhan within 14 days. Fourteen $(51.85 \%)$ patients who had neither visited the city nor had been in contact with Wuhan residents were exposed to infected patients within 14 days. The epidemiological history of two $(7.41 \%)$ of the patients was unknown. Twenty-five $(92.59 \%)$ were cluster cases.

Compared with the young/middle-aged group, the elderly group were more likely to suffer from hypertension $(51.85 \%$ vs. $9.38 \%, P<0.001)$, cardiovascular disease $(25.93 \%$ vs. $6.25 \%, P<0.001)$, malignancy $(14.81 \%$ vs. $1.56 \%, P=0.042)$, cerebrovascular disease $(11.11 \%$ vs. $0 \%, P=0.039$ ), and chronic obstructive pulmonary disease (COPD) $(11.11 \%$ vs. $0 \%, P=0.039)$. The proportion of the patients who had more than two comorbidities in the elderly group was higher than that in the young/middle-aged group (33.33\% vs. $4.69 \%, P=0.001$ ), as well as than that in the proportion of the patients with one comorbidity $(37.04 \%$ vs. $10.94 \%, P=0.004)$.

According to the clinical classification adopted, the proportion of the critically ill patients in the elderly group was 
Table 1 Demographic data, epidemical history comorbidities and clinical classification of patients with COVID-19

\begin{tabular}{|c|c|c|c|c|c|}
\hline & $\begin{array}{l}\text { Total } \\
n=91\end{array}$ & $\begin{array}{l}\text { Under } 65 \\
n=64\end{array}$ & $\begin{array}{l}\text { Over } 65 \\
n=27\end{array}$ & $t$ or $\chi^{2}$ or $U$ & $P$ value \\
\hline Gender (male) & 39 & 27 & 12 & 0.039 & 0.84 \\
\hline \multicolumn{6}{|l|}{ Epidemical history } \\
\hline Local residents of Wuhan & 24 & 14 & 10 & 2.248 & 0.13 \\
\hline Non local residents: recently contacted with Wuhan residents & 21 & 20 & 1 & 8.117 & $0.004 *$ \\
\hline Exposure to infected patients who had not visited Wuhan & 41 & 27 & 14 & 0.716 & 0.40 \\
\hline Unknown exposure & 5 & 3 & 2 & 0 & 0.99 \\
\hline Cluster cases $(n, \%)$ & 71 & 46 & 25 & 4.753 & $0.029 *$ \\
\hline \multicolumn{6}{|l|}{ Comorbidities } \\
\hline Hypertension & 20 & 6 & 14 & 19.98 & $<0.001 *$ \\
\hline Cardiovascular disease & 11 & 4 & 7 & 5.19 & $<0.001 *$ \\
\hline Diabetes mellitus & 5 & 3 & 2 & 0 & 1.0 \\
\hline Malignancy & 5 & 1 & 4 & 4.124 & $0.042 *$ \\
\hline Cerebrovascular disease & 3 & 0 & 3 & 4.281 & $0.039 *$ \\
\hline Chronic obstructive pulmonary disease & 3 & 0 & 3 & 4.281 & $0.039 *$ \\
\hline Viral hepatitis & 2 & 1 & 1 & 0 & 1.0 \\
\hline Chronic kidney diseases & 1 & 0 & 1 & 0.2 & 0.66 \\
\hline No comorbidity & 62 & 54 & 8 & 26.211 & $<0.001 *$ \\
\hline 1 comorbidity & 17 & 7 & 10 & 8.515 & $0.004^{*}$ \\
\hline$\geq 2$ comorbidity & 12 & 3 & 9 & 11.224 & $0.001 *$ \\
\hline \multicolumn{6}{|l|}{ Clinical classification } \\
\hline Mild type & 0 & 0 & 0 & & \\
\hline Common type & 69 & 56 & 13 & 16.041 & $<0.001^{*}$ \\
\hline Severe type & 13 & 8 & 5 & 0.178 & 0.67 \\
\hline Critical ill type & 9 & 0 & 9 & 20.082 & $<0.001^{*}$ \\
\hline Time taken for diagnosis (day) & $5.0(3.0-7.0)$ & $4.5(3.0-6.0)$ & $5.0(2.0-8.0)$ & -0.615 & 0.11 \\
\hline Smoking history & 6 & 4 & 2 & 0 & 1.0 \\
\hline Former smoking & 3 & 1 & 2 & & \\
\hline Current smoking & 3 & 3 & 0 & & \\
\hline
\end{tabular}

Data were shown as mean \pm standard deviation, median $(\mathrm{Q} 1, \mathrm{Q} 3)$, or $n(\%) . P$ values indicate differences between the elderly group and the young/middle-aged group

COVID-19 Coronavirus disease 2019

$* P<0.05$ was considered statistically significant

significantly higher with the one in the young/middle-aged group $(33.3 \%$ vs. $0 \%, P<0.001)$.

\section{Clinical features}

The clinical features are summarized in Table 2. Expectoration $(55.56 \%$ vs. $23.44 \%, P=0.003)$ and dyspnea $(51.85 \%$ vs. $15.63 \%, P<0.001)$ were higher in the elderly group than in the young/middle-aged group. However, the level of myalgia $(3.70 \%$ vs. $26.56 \%, P=0.012)$ was lower in the elderly group than in the young/middle-aged group. The respiratory rate in the elderly group was higher than that in the young/ middle-aged group (20.0 breaths/min vs. 20.0 breaths/min, $P=0.02)$.

\section{Laboratory results and imaging features}

The laboratory results on admission are listed in Table 3 . The lymphocyte count $\left(0.81 \times 10^{9} / \mathrm{L}\right.$ vs. $1.07 \times 10^{9} / \mathrm{L}$, $P=0.04)$ and serum albumin (ALB) $(31.89 \pm 6.83 \mathrm{~g} / \mathrm{L} \mathrm{vs}$. $36.46 \pm 4.30 \mathrm{~g} / \mathrm{L}, P<0.001)$ were lower in the elderly group than in the young/middle-aged group. Conversely, C-reactive protein $(\mathrm{CRP})(44.80 \mathrm{mg} / \mathrm{L}$ vs. $14.10 \mathrm{mg} / \mathrm{L}, P=0.003)$ and procalcitonin (PCT) $(0.14 \mathrm{ng} / \mathrm{mL}$ vs. $0.11 \mathrm{ng} / \mathrm{mL}, P=0.002)$ were higher in the elderly than in the young/middle-aged. In addition, the levels of aspartate transaminase (AST) (37.00 U/L vs. $30.00 \mathrm{U} / \mathrm{L}, P<0.001)$, creatine kinase (CKMB) ( $0.83 \mathrm{ng} / \mathrm{mL}$ vs. $0.26 \mathrm{ng} / \mathrm{mL}, P=0.001)$, myoglobin (MYO) $(78.00 \mathrm{ng} / \mathrm{mL}$ vs. $35.50 \mathrm{ng} / \mathrm{mL}, P<0.001)$, and troponin I (TNI) $(0.021 \mathrm{ng} / \mathrm{mL}$ vs. $0.01 \mathrm{ng} / \mathrm{mL}, P=0.001)$ were 
Table 2 Clinical presentations in patients with COVID-19

\begin{tabular}{|c|c|c|c|c|c|}
\hline Symptoms and signs $(n, \%$ or mean \pm S.D. $)$ & $\begin{array}{l}\text { Total } \\
n=91\end{array}$ & $\begin{array}{l}\text { Under } 65 \\
n=64\end{array}$ & $\begin{array}{l}\text { Over } 65 \\
n=27\end{array}$ & $t$ or $\chi^{2}$ or $U$ & $P$ value \\
\hline Fever & 78 & 55 & 23 & 0 & 1.0 \\
\hline $\begin{array}{l}\text { Maximum body temperature during the } \\
\text { course of the disease }\end{array}$ & $38.52 \pm 0.57$ & $38.51 \pm 0.58$ & $38.54 \pm 0.56$ & -0.242 & 0.81 \\
\hline$<37.3{ }^{\circ} \mathrm{C}$ & 13 & 9 & 4 & 0 & 1.0 \\
\hline $37.3-38^{\circ} \mathrm{C}$ & 17 & 13 & 4 & 0.378 & 0.54 \\
\hline $38.1-39^{\circ} \mathrm{C}$ & 49 & 35 & 14 & 0.061 & 0.80 \\
\hline$>39{ }^{\circ} \mathrm{C}$ & 12 & 7 & 5 & 0.406 & 0.52 \\
\hline Duration of fever & $8.94 \pm 4.13$ & $8.82 \pm 3.38$ & $9.22 \pm 5.62$ & -0.317 & 0.75 \\
\hline Cough & 59 & 40 & 19 & 0.516 & 0.47 \\
\hline Expectoration & 30 & 15 & 15 & 8.864 & $0.003 *$ \\
\hline Fatigue & 24 & 17 & 7 & 0.004 & 0.95 \\
\hline Dyspnea & 24 & 10 & 14 & 12.834 & $<0.001^{*}$ \\
\hline Myalgia & 18 & 17 & 1 & 6.253 & $0.012 *$ \\
\hline Pharyngalgia & 16 & 14 & 2 & 1.836 & 0.18 \\
\hline Nausea & 11 & 6 & 5 & 0.757 & 0.38 \\
\hline Chills & 10 & 9 & 1 & 1.159 & 0.28 \\
\hline Nasal congestion & 10 & 8 & 2 & 0.117 & 0.73 \\
\hline Abdominal pain & 3 & 3 & 0 & 0.251 & 0.62 \\
\hline Respiratory rate & $20.0(20.0-21.0)$ & $20(19-20.75)$ & $20.0(20.0-22.0)$ & -2.246 & $0.02 *$ \\
\hline Heart rate & $82(80-90)$ & $82(80-90)$ & $82(75-90)$ & -0.515 & 0.61 \\
\hline Mean arterial pressure $(\mathrm{mmHg})$ & $90.49 \pm 13.65$ & $89.65 \pm 14.07$ & $92.49 \pm 12.64$ & -0.906 & 0.37 \\
\hline Blood oxygen saturation, $\%$ median(range) & $97.60(95.25-99.00)$ & $97.80(95.30-99.00)$ & $97.30(94.60-98.30)$ & -0.961 & 0.34 \\
\hline
\end{tabular}

Data were shown as mean \pm standard deviation, median $(\mathrm{Q} 1, \mathrm{Q} 3)$, or $n(\%) . P$ values indicate differences between the elderly group and the young/middle-aged group

COVID-19 Coronavirus disease 2019.

$* P<0.05$ was considered statistically significant

significantly higher in the elderly group than in the young/ middle-aged group.

The major $\mathrm{CT}$ abnormalities observed were ground glass opacity and patch shadow. All of the elderly patients had bilateral pneumonia.

\section{Treatment and clinical outcomes}

The treatment applied and clinical outcomes are summarized in Table 4. The proportions of corticosteroid therapy $(48.15 \%$ vs. $25.00 \%, P=0.03)$ and human immunoglobulin therapy ( $22.22 \%$ vs. $1.56 \%, P=0.003)$ were higher in the elderly group as compared with those the young/middleaged group.

Nine of the $10(10.99 \%)$ patients admitted to the ICU were the elderly. Of the seven $(7.69 \%)$ patients that received invasive mechanical ventilation, six $(85.71 \%)$ were older patients, (four of which were switched to extracorporeal membrane oxygenation (ECMO). In the elderly, two patients received VV- ECMO treatment, and one patient received veno-arterial femoro-femoral ECMO treatment because of respiratory failure complicated with cardiogenic shock. All three elderly patients had been prone positioned before ECMO implantation. At the time of ECMO implantation, the median $\mathrm{PaO}_{2} / \mathrm{FiO}_{2}$ was 64.93 (range 45.4-89.9), and the median blood flow was $4.03 \mathrm{~L} / \mathrm{min}$ (range 3.76-4.32L/ min). Under ECMO, two patients had gastrointestinal bleeding complications. As of March 7, 2020, two patients were still in the ICU, one patient died from septic shock 4 days after ECMO implantation.

The complications in the 27 elderly patients included pleural effusion $[10,(37.04 \%)]$, secondary infection $(7$, [25.93\%]), kidney damage (7, [25.93\%]), acute cardiac injury [6, (22.22\%)], liver injury [5, (18.52\%)], arrhythmia $[4,(14.81 \%)]$, acute respiratory distress syndrome (ARDS) [3, (11.11\%)], sepsis [3, (11.11\%)], septic shock [2, $(7.41 \%)]$, and cardiogenic shock [2, (7.41\%)].

As of March 7, a total number of $20(74.07 \%)$ of the 27 elderly patients were discharged, whereas two $(7.41 \%)$ were still in the ICU for further treatment, and five (18.52\%) died. It is noteworthy that all of the young/middle-aged patients discharged. No difference was found in the time taken for 
Table 3 Laboratory results and imaging findings in patients with COVID-19

\begin{tabular}{|c|c|c|c|c|c|}
\hline Variable & $\begin{array}{l}\text { Total } \\
n=91\end{array}$ & $\begin{array}{l}\text { Under } 65 \\
n=64\end{array}$ & $\begin{array}{l}\text { Over } 65 \\
n=27\end{array}$ & $t$ or $\chi^{2}$ or $U$ & $P$ value \\
\hline $\mathrm{WBC}, \times 10^{9} / \mathrm{L}$ & $4.13(3.48-5.64)$ & $4.03(3.44-4.93)$ & $5.86(3.61-6.84)$ & -3.19 & $0.003 *$ \\
\hline Lymphocyte count, $10^{9} / \mathrm{L}$ & $0.98(0.74-1.38)$ & $1.07(0.74-1.395)$ & $0.81(0.53-1.04)$ & -2.055 & $0.04 *$ \\
\hline Neutrophil count, $\times 10^{9} / \mathrm{L}$ & $2.79(1.85-4.05)$ & $2.40(1.79-3.21)$ & $4.11(2.34-5.67)$ & -3.688 & $0.001 *$ \\
\hline $\operatorname{PLT}\left(\times 10^{9} / \mathrm{L}\right)$ & $190.0(152.0-230.0)$ & $186.5(149.50-226.25)$ & $193.0(158.0-233.0)$ & -0.413 & 0.68 \\
\hline $\operatorname{ALT}(\mathrm{U} / \mathrm{L})$ & $30.0(21.0-51.0)$ & $31.00(23.00-50.00)$ & $27.00(20.00-52.00)$ & -0.582 & 0.56 \\
\hline AST (U/L) & $32.0(22.0-48.0)$ & $30.00(22.00-42.00)$ & $37.00(27.00-54.00)$ & -3.558 & $<0.001 *$ \\
\hline TBIL $(\mu \mathrm{mol} / \mathrm{L})$ & $9.2(6.9-12.9)$ & $8.90(6.68-12.35)$ & $11.30(7.00-14.90)$ & -1.46 & 0.14 \\
\hline $\mathrm{DBIL}(\mu \mathrm{mol} / \mathrm{L})$ & $1.90(1.30-2.70)$ & $1.90(1.30-2.50)$ & $2.20(1.40-3.20)$ & -1.217 & 0.23 \\
\hline $\operatorname{ALB}(g / L)$ & $35.11 \pm 5.55$ & $36.46 \pm 4.30$ & $31.89 \pm 6.83$ & 3.858 & $<0.001^{*}$ \\
\hline Crea (umol/L) & $64.0(55.0-78.0)$ & $64.0(55.0-75.0)$ & $67.0(56.0-91.0)$ & -1.23 & 0.22 \\
\hline $\mathrm{CK}(\mathrm{U} / \mathrm{L})$ & $76.00(46.0-128.00)$ & $66.50(46.00-115.75)$ & $99.00(45.00-225.42\}$ & -1.482 & 0.14 \\
\hline CK-MB (ng/mL) & $0.31(0.16-0.90)$ & $0.26(0.09-0.4485)$ & $0.83(0.38-1.91)$ & -4.05 & $0.001 *$ \\
\hline MYO (ng/ mL) & $47.0(31.0-77.00)$ & $35.50(28.75-60.0)$ & $78.00(47.00-182.00)$ & -3.924 & $<0.001^{*}$ \\
\hline TNI (ng/ mL) & $0.01(0.01-0.02)$ & $0.01(0.01-0.02)$ & $0.021(0.01-0.069)$ & -3.253 & $0.001 *$ \\
\hline CRP (mg/L) & $18.85(5.40-51.88)$ & $14.10(3.20-26.90)$ & $44.80(13.50-104.90)$ & -2.928 & $0.003 *$ \\
\hline PCT (ng/ mL) & $0.11(0.10-0.15)$ & $0.11(0.10-0.13)$ & $0.14(0.11-0.22)$ & -3.074 & $0.002 *$ \\
\hline $\mathrm{LAC}(\mathrm{mmol} / \mathrm{L})$ & $1.27(0.93-1.74)$ & $1.24(0.92-1.46)$ & $1.69(0.94-1.99)$ & -1.869 & 0.062 \\
\hline PT (s) & $12.60(11.90-13.20)$ & $12.50(11.90-13.08)$ & $12.80(12.20-13.7)$ & -1.487 & 0.14 \\
\hline PTA (\%) & $75.45 \pm 10.03$ & $76.15 \pm 8.69$ & $73.81 \pm 12.70$ & 1.103 & 0.31 \\
\hline INR (INR) & $1.13(1.07-1.17)$ & $1.11(1.06-1.17)$ & $1.14(1.10-1.22)$ & -1.61 & 0.11 \\
\hline FIB $(g / L)$ & $3.15(2.71-4.24)$ & $3.08(2.61-3.89)$ & $3.94(2.81-4.51)$ & -1.582 & 0.11 \\
\hline \multicolumn{6}{|l|}{ Imaging findings } \\
\hline $\begin{array}{l}\text { Bilateral patchy shadows or } \\
\text { ground glass opacity no. }(\%)\end{array}$ & 82 & 55 & 27 & 2.783 & 0.10 \\
\hline
\end{tabular}

Data were shown as mean \pm standard deviation, median $(\mathrm{Q} 1, \mathrm{Q} 3)$, or $n(\%) . P$ values indicate differences between the elderly group and the young/middle-aged group

WBC White blood cell count, PLT Platelet, ALT Alanine transaminase, AST Aspartate transaminase, TBIL Total bilirubin, DBIL Direct bilirubin, $A L B$ Albumin, Crea Creatinine, $C K$ Creatine kinase, $C K M B$ Creatine kinase-MB, $M Y O$ Myoglobin, TNI Troponin I, $C R P$ C-reactive protein, $P C T$ Procalcitonin, LAC Lactic acid, PT Prothrombin time, INR International normalized ratio, FIB Fibrinogen

$* P<0.05$ was considered statistically significant

receiving nucleic acid-negative results $(14.20 \pm 6.90$ days vs. $12.41 \pm 3.92$ days, $P=0.23$ ) and $\mathrm{CT}$ image improvement (15.0 days vs. 14.0 days, $P=0.86$ ) between the two groups in discharged patients.

\section{Prognostic factors associated with the mortality}

In univariate analysis, for all the patients, age, cardiovascular disease, COPD, white blood cell (WBC), ALB and CRP were associated with mortality. In multivariable analysis, for all the patients, age was independently associated with mortality (OR $0.8295 \%$ CI $0.70-0.97, P=0.019$ ).

\section{Discussion}

This descriptive case series were initially focused on the clinical characteristics and outcomes in elderly with COVID-19 in detail. As of March 7, 27 elderly were enrolled in this study. Of them, nine $(33.33 \%)$ required ICU care and a high level of respiratory support, five died (18.52\%), and two (7.41\%) remained hospitalized at the time of preparing this manuscript. The mortality of COVID-19 in the elderly was high. Recent study estimated the risk for death from COVID-19 in China were as high as 
Table 4 Treatments, complications and outcomes in patients with COVID-19

\begin{tabular}{|c|c|c|c|c|c|}
\hline & $\begin{array}{l}\text { Total } \\
n=91\end{array}$ & $\begin{array}{l}\text { Under } 65 \\
n=64\end{array}$ & $\begin{array}{l}\text { Over } 65 \\
n=27\end{array}$ & $t$ or $\chi^{2}$ or $U$ & $P$ value \\
\hline \multicolumn{6}{|l|}{ Treatment $(n, \%)$} \\
\hline Antiviral therapy & 30 & 21 & 9 & 0.002 & 0.96 \\
\hline Antibiotics therapy & 21 & 9 & 12 & 9.874 & $0.002 *$ \\
\hline Systemic corticosteroid therapy & 29 & 16 & 13 & 4.686 & $0.03 *$ \\
\hline Human immunoglobulin & 7 & 1 & 6 & 8.69 & $0.003 *$ \\
\hline \multicolumn{6}{|l|}{ Oxygen support } \\
\hline Nasal cannula & 62 & 35 & 27 & 17.957 & $<0.001 *$ \\
\hline Non-invasive ventilation or high-flow nasal cannula & 3 & 0 & 3 & 4.281 & $0.039 *$ \\
\hline Invasive mechanical ventilation & 7 & 1 & 6 & 8.69 & $0.003^{*}$ \\
\hline Invasive mechanical ventilation and ECMO & 4 & 1 & 3 & 2.161 & 0.14 \\
\hline ICU care & 10 & 1 & 9 & 16.481 & $<0.001^{*}$ \\
\hline Continuous renal replacement therapy & 4 & 1 & 3 & 2.161 & 0.14 \\
\hline \multicolumn{6}{|l|}{ Complications $(n, \%)$} \\
\hline Pleural effusion & 13 & 3 & 10 & 1 & $<0.001^{*}$ \\
\hline Secondary infection & 12 & 5 & 7 & 3.975 & $0.046^{*}$ \\
\hline Kidney injury & 12 & 5 & 7 & 3.975 & $0.046^{*}$ \\
\hline Acute cardiac injury & 7 & 1 & 6 & 8.69 & $0.003 *$ \\
\hline Liver injury & 7 & 2 & 5 & 4.354 & $0.037 *$ \\
\hline Arrhythmia & 5 & 1 & 4 & 4.124 & $0.042 *$ \\
\hline Acute respiratory distress syndrome & 4 & 1 & 3 & 2.161 & 0.14 \\
\hline Sepsis & 4 & 1 & 3 & 2.161 & 0.14 \\
\hline Septic shock & 3 & 1 & 2 & 0.614 & 0.43 \\
\hline Cardiogenic shock & 2 & 0 & 2 & 2.014 & 0.16 \\
\hline \multicolumn{6}{|l|}{ Outcomes ( $\%$ or mean \pm S.D.) } \\
\hline Time taken for CT imaging improvement & $14.50(12.0-17.0)$ & $14.0(12.0-16.0)$ & $15.0(11.0-18.0)$ & -0.182 & 0.86 \\
\hline Time taken for nucleic acid negative & $12.91 \pm 4.97$ & $12.41 \pm 3.92$ & $14.20 \pm 6.90$ & -1.224 & 0.23 \\
\hline Length of hospital stay (days) & $13.0(10.0-18.0)$ & $13.0(10.0-16.00)$ & $16.50(10.0-21.0)$ & -1.276 & 0.20 \\
\hline In-hospital mortality & 5 & 0 & 5 & 9.228 & $0.002 *$ \\
\hline Discharge & 83 & 63 & 20 & 11.183 & $0.001 *$ \\
\hline Inpatient treatment & 3 & 1 & 2 & 0.614 & 0.43 \\
\hline
\end{tabular}

Data were shown as mean \pm standard deviation, median $(\mathrm{Q} 1, \mathrm{Q} 3)$, or $\mathrm{n}(\%) . P$ values indicate differences between the elderly group and the young/middle-aged group

$* P<0.05$ was considered statistically significant

$12 \%$ in the center of outbreak [7].Therefore, it was exceedingly important to summarize the clinical characteristics of the elderly population with COVID-19.

Recent studies have shown that more than half of the COVID-19 patients were male in China [8,9], which is consistent with the Iran data (66.0\%) [10]. However, in Korean data, only $37.7 \%$ were male [11]. We observed slightly more women than men $(57.14 \%$ vs $42.86 \%)$ in total confirmed adults cases. Whether the gender may be associated with the prevalence of COVID-19 or not needs further study.

Importantly, more than two-thirds of the elderly had underlying comorbidities including hypertension, cardiovascular disease, malignancy, diabetes mellitus, COPD, and cerebrovascular disease. The ratio of critically ill patients in the elderly group was significantly higher. These findings suggest that the elderly infected with SARS-CoV-2 are more likely to suffer from the critically ill type of COVID-19. The underlying comorbidity may be one of the risk factors for that critical illness. Therefore, elderly patients need special treatment plans such as the inclusion of antihypertensive and hypoglycemic therapy [12]. Studies reported that SARS-CoV-2 binds to the target cells through ACE2 and subsequently down-regulates ACE2 expression [13]. ACE2 is an key enzyme that physiologically counters RAAS activation. The effects of ACE inhibitors and ARB on ACE2 expression are uncertain. It suggests that RAAS inhibitors should be continued in patients in otherwise stable condition who are with COVID-19 [14]. Therefore, for high-risk 
elderly patients, the application of RAAS inhibitors needs to be fully evaluated.

The symptoms of expectoration and dyspnea were more common in the elderly.These results are consistent with the ones of a previous study which was on coronavirus-associated respiratory disease in older patients [15]. In addition,the increased respiratory rate might be a sign of disease progression, which indicates that more attention should be paid to respiratory symptoms, especially in the elderly.

Studies reported that pleural effusion was rare in mild adult patients, but it was more frequently observed in critically ill COVID-19 patients [16, 17]. In our study, some elderly patients developed slightly pleural effusion within 2-4 weeks after COVID-19 pneumonia. The relationship between pleural effusion and prognosis in elderly COVID19 patients deserves further investigation. Besides pleural effusion, SARS-CoV-2 may also cause damage to other organs, including the heart, the blood, and the immune system $[18,19]$. Prolonged prothrombin time was also observed in a previous investigation [20]. More recent studies found pathological features of COVID-19, including bilateral diffuse alveolar damage with cellular fibromyxoid exudate and degeneration and necrosis of parenchymal cells spleen and in other organs $[21,22]$. These earlier pathological findings confirm that SARS-CoV-2 infection can cause multiple organ injuries. In view of the above, monitoring and prevention of potential multiple organs injuries in elderly are highly necessary.

So far, no effective drug has been identified for treatment of this disease. For the patients with mild symptoms, symptomatic therapy is the main treatment. However, the severe and critically ill patients need individual and comprehensive treatment, especially in elderly with comorbidities. Experts from the Chinese Thoracic Society recommended short courses of corticosteroids at low-to-moderate doses, used prudently, for critically ill patients with COVID-19 [23]. In our study, methylprednisolone was given to the patients whose symptoms worsened and/or CT imaging showed progresses rapid disease progression. The dosage of corticosteroids was adjusted according to the degrees of improvement of the symptoms and the resolution of fever. Nearly half of the elderly patients received corticosteroids treatment, eight of which were discharged, and three died. The corticosteroid dose in elderly was ranged from $60-160 \mathrm{mg} / \mathrm{d}$. The efficacy and outcomes of corticosteroid therapy in elderly with COVID-19 needs further confirmation. Respiratory support was important in COVID-19 therapy. In the present study, we found that the older patients were more likely to receive high level of respiratory support, such as high-flow nasal cannula and non-/invasive mechanical ventilation. In severe COVID-19 cases, especially in elderly whose hypoxic respiratory failure unable to be supported by mechanical ventilation, the role of ECMO as a rescue therapy remains unknown. Limited data showed the mortality of severe COVID-19 ECMO cases ranged from 42-83\% [9, 24, 25]. Study has shown that more ECMO programs outside Hubei applied ECMO in older patients (age > 65), compared with ECMO programs in Hubei. We described our experience on the management of ECMO therapy in the severe COVID19 elderly cases. The elderly cases had several challenging aspects including hyperdynamic cardiac function and coagulopathy. It is necessary to summarize the management and outcomes with ECMO.

This study has some limitations. First, as a single-center trial, the sample size was relatively small, and thus multicenter larger-scale studies are required to confirm our findings. Second, as the designated hospital was in Beijing, patients with severe conditions were admitted to our hospital, which might have caused biased results.

In conclusion, in the process of establishing the impact of COVID-19 on the elderly, we have identified the major clinical characteristics and have presented our experience in the treatment of elderly with COVID-19.

Author contributions All authors contributed to the study conception and design. Material preparation, data collection and analysis were performed by WZ, WH, RJ and LL. The first draft of the manuscript was written by $\mathrm{WZ}, \mathrm{BX}$ and $\mathrm{ZH}$, and all authors commented on previous versions of the manuscript. All authors read and approved the final manuscript.

\section{Compliance with ethical standards}

Conflicts of interest There are no potential conficts of interest or any financial or personal relationship with other people or organizations that could inappropriately bias conduct and findings of this study.

Research involving human participants and/or animals Our work does not involve any violation of human and animal rights.

Ethics approval This study was conducted in accordance with the Declaration of Helsinki. The requirement for written informed consent was waived, given the context of emerging infectious diseases.

Consent to participate Verbal informed consent was obtained prior to the research.

Availability of data and material The datasets generated during the current study are available from the corresponding author on reasonable request.

\section{References}

1. Huang C, Wang Y, Li X, Ren L, Zhao J, Hu Y et al (2020) Clinical features of patients infected with 2019 novel coronavirus in Wuhan, China. The Lancet 395(10223):497-506

2. World Health Organization. (2020) Clinical management of severe acute respiratory infection when novel coronavirus ( $\mathrm{nCoV})$ infection is suspected. https://www.who.int/publications-detail/clini 
cal-management-of-severe-acute-respiratory-infection-whennovelcoronavirus-(ncov)-infection-is-suspected. Accessed $2 \mathrm{Feb}$ 2020

3. Lu R, Zhao X, Li J, Niu P, Yang B, Wu H et al (2020) Genomic characterization and epidemiology of 2019 novel coronavirus: implications for virus origins and receptor binding. The Lancet 395:565-574

4. Liu W, Tao ZW, Lei W, Ming-Li Y, Kui L, Ling Z et al (2020) Analysis of factors associated with disease outcomes in hospitalized patients with 2019 novel coronavirus disease. Chin Med J 133(9):1032-1038

5. Zhang JJ, Dong X, Cao YY, Yuan YD, Yang YB, Yan YQ et al (2020) Clinical characteristics of 140 patients infected by SARSCoV-2 in Wuhan. China Allergy 00:1-12

6. National Health and Health Commission of China. (2020)Diagnosis and treatment protocol for novel coronavirus infection-induced pneumonia version 7 (trial). [in Chinese] https://www.nhc.gov.cn/ yzygj/s7653p/202003/46c9294a7dfe4cef80dc7f5912eb1989/files /ce3e6945832a438eaae415350a8ce964.pdf.Accessed 2 Feb 2020

7. Mizumoto K, Chowell G (2020) Estimating risk for death from 2019 novel coronavirus disease, China, January-February 2020. Emerg Infect Dis 26(6):1251-1256

8. Guan WJ, Ni ZY, Hu Y, Liang WH, Ou CQ, He JX et al (2020) Clinical characteristics of coronavirus disease 2019 in China. The New Engl J Med 382:1708-1720

9. Yang X, Yu Y, Xu J, Shu H, Xia J, Liu H et al (2020) Clinical course and outcomes of critically ill patients with SARS-CoV-2 pneumonia in Wuhan, China: a single-centered, retrospective, observational study. The Lancet Respir Med 8:475-481

10. Nikpouraghdam M, Jalali Farahani A, Alishiri G, Heydari S, Ebrahimnia M, Samadinia H et al (2020) Epidemiological characteristics of coronavirus disease 2019 (COVID-19) patients in IRAN: a single center study. J Clin Virol 127:104378

11. Korean Society of Infectious Diseases, Korean Society of Pediatric Infectious Diseases, Korean Society of Epidemiology, Korean Society for Antimicrobial Therapy, Korean Society for Healthcare-associated Infection Control and Prevention, Korea Centers for Disease Control and Prevention (2020) Report on the epidemiological features of coronavirus disease 2019 (COVID19) outbreak in the republic of Korea from January 19 to March 2, 2020. J Korean Med Sci 35(10):e112

12. Wang T, Du Z, Zhu F, Cao Z, An Y, Gao Y et al (2020) Comorbidities and multi-organ injuries in the treatment of COVID-19. The Lancet 395(10228):e52

13. Gurwitz D (2020) Angiotensin receptor blockers as tentative SARSCoV-2 therapeutics. Drug Dev Res. https://doi.org/10.1002/ ddr. 21656

14. Vaduganathan M, Vardeny O, Michel T, McMurray JJV, Pfeffer MA, Solomon SD (2020) (2020) Renin-angiotensin-aldosterone system inhibitors in patients with COVID-19. The New Engl J Med 382:1653-1659

15. Gorse GJ, Donovan MM, Patel GB, Balasubramanian S, Lusk RH (2015) Coronavirus and other respiratory illnesses comparing older with young adults. The Am J Med 128(11):1251.e11-20

16. Han R, Huang L, Jiang H, Dong J, Peng H, Zhang D (2020) Early Clinical and CT manifestations of coronavirus disease 2019 (COVID-19) pneumonia. AJR Am J Roentgenol 17:1-6

17. Fu Z, Tang N, Chen Y, Ma L, Wei Y, Lu Y et al (2020) CT features of COVID-19 patients with two consecutive negative RT-PCR tests after treatment. Sci Rep 10(1):11548

18. Chen N, Zhou M, Dong X, Qu J, Gong F, Han Y et al (2020) Epidemiological and clinical characteristics of 99 cases of 2019 novel coronavirus pneumonia in Wuhan, China: a descriptive study. The Lancet 395(10223):507-513

19. Wang D, Hu B, Hu C, Zhu F, Liu X, Zhang J et al (2020) Clinical characteristics of 138 hospitalized patients with 2019 novel coronavirus-infected pneumonia in Wuhan, China. JAMA 323(11):1061-1069

20. Zhou F, Yu T, Du R, Fan G, Liu Y, Liu Z et al (2020) Clinical course and risk factors for mortality of adult inpatients with COVID-19 in Wuhan, China: a retrospective cohort study. The Lancet 395(10229):1054-1062

21. Xu Z, Shi L, Wang Y, Zhang J, Huang L, Zhang C et al (2020) Pathological findings of COVID-19 associated with acute respiratory distress syndrome. The Lancet Respir Med 8:420-422

22. Yao XH, Li TY, He ZC, Ping YF, Liu HW, Yu SC et al (2020) A pathological report of three COVID-19 cases by minimally invasive autopsies. Zhonghua Bing Li Xue Za Zhi 49:E009

23. Zhao JP, Hu Y, Du RH, Chen ZS, Jin Y, Zhou M et al (2020) Expert consensus on the use of corticosteroid in patients with 2019-nCoV pneumonia. Zhonghua Jie He He Hu Xi Za Zhi (in Chinese) 43(3):183-184

24. Li X, Guo Z, Li B, Zhang X, Tian R, Wu W et al (2020) Extracorporeal membrane oxygenation for coronavirus disease 2019 in Shanghai, China. ASAIO J 66:475-481

25. Zeng Y, Cai Z, Xianyu Y, Yang BX, Song T, Yan Q (2020) Prognosis when using extracorporeal membrane oxygenation (ECMO) for critically ill COVID-19 patients in China: a retrospective case series. Crit Care 24(1):148

Publisher's Note Springer Nature remains neutral with regard to jurisdictional claims in published maps and institutional affiliations. 